\title{
LOS CENTROS DE HIGIENE LNFANTIL EN MONTREAL
}

\author{
Por el Dr. WERNER BUSTAMANTE E.
}

Para apreciar mejor la atención que el niño recibe en la ciudad d: Montreal, Canadá, es necesario recordar que dicha ciudad se encuentra ubicada en la provincia de Quebec, a las márgenes del rio San Lorenzo y cuenta con una población de un millón doscientcs mil habitantes, siendo. por lo tanto. la ciudad más grande y más poblada del Canadá. Viven alí 750 mil canadienses de origen francés-canadiense, $250 \mathrm{mil}$ de crigen anglo-sajón, estando el resto formado por descendientes de crigen irlandés, judio, italiano, polaco, etc.

La ciudad de Montreal cuenta con tres grandes organismos dedicados a la atención preventiva materno-infantil, ellos son: la División de Higiene Infantil, dependiente del Departamento de Salud de la ciudad; la Federación de Higiene Infantil, y la Asociación de Bienestar Infantil.

\section{División de Higiene Infantil.}

La Municipalidad de Montreal, por intermedio det "Departamento de Salud" tiene a su cargo el control sanitario de la ciudad. Entre las distintas divisiones en que está dividido este Departamento figura la de "Higiene Infantil" (Child Hygiene Divisicn), organizado en 1918. Este servicic se encuentra, a su vez. dividido en varias secciones, siendo las más importantes la sección pre-natal, lactantes; preescolares; el servicio de inspección médica escolar; higiene dental; nutrición; enfermeras visitadoras y distritos sanitarios. Las finalidades que persigue la División de Higiene Infantil son las de proteger la salud de las mujeres embarazadas, luchar contra la mortalidad infantil, vigilar el desarrollo 
del niño desde su nacimiento hasta la edad en que deja la escuela, y enseñar los hábitos de higiene.

Para facilitar el trabajo de vigilancia y control, la ciudad se encuentra dividida en 6 distritos, con una población aproximada de 100 a $130 \mathrm{mil}$ habitantes cada uno. Frente a cada distrito se encuentra un médico jefe, que representa al Director del Departamento de Salud y tiene a su cargo la resfonsabilidad del estado sanitario de ese sector. En cada distrito existe un centro llamado "Centro de Higiene" '(Centre d'Hygiène), donde se encuentran las oficinas generales del distrito. las clínicas pre-natales, de lactantes, pre-escolares, dentales, etc. Estos distritos se encuentran, a su vez, divididos en numerosos sub-distritos, que en total suman 19 y que también cuentan con pequeños centros encargados de la higiene infantil. Estos servicios disponen en total, con 56 clínicas para lactantes y pre-escolares; 6 clínicas pre-ratales y 2 clínicas al aire libre, que funcionan solamente durante los meses de verano.

Durante el año 1945. las 56 clinicas municipales de Higiene Infantil inscribieron 23.734 lactantes y 1.1 .527 preescolares. Los exámenes y consultas alcanzaton a 95,615 y las visitas reatizadas por tas enfermeras a domicilio a 38.795 . Se vacunaron contra la viruela 16,530 personas: 12.543 niños se inmunizaton contra la difteria y 22,145 contra la coqueluche.

Como en todo Centro dedicado a esta clase de atención. gran importancia le dan a la educación de la madre en el arte de cuidar a sus hijos y a la manera de alimentarlos, tratando de evitar los prejuicios engendrados pot la ignorancia o la negligencia. A los niños de la edad pre-escolar se les examina por el médico y dentista cada 6 meses y le controlan su peso cada mes. si es posible. Se procura que en esta edad el níno se encuentre inmunizado contra la difteria, coqueluche, virue1a. etc. Semanas antes que el niño ingrese por primera vez a la escuela, se le hace un nuevo examen, dando tiempo así de corregir cualquiera alteración que pudiera. interferit con. sus estudios.

De los 56 Centros con que cuenta la Municipalidad, sólo visitó los 3 más grandes, cuales son: El Centro Maisonneuve, Delorimier y Laurier, ubicados en el barrio francés, o sea, en el sector Este de la ciudad.

Centro Maisonneuve: Ocupa una mederna y cómoda casa de habitación, arreglada en forma adecuada para que pueda funcionar el Centro de Higiene. La clientela está for- 
mada especialmente por esposas e hijos de obreros, empleados, comerciantes, etc. Dos días a la semana se atiende a los niños de las familias de habla francesa $y$ dos dias para las familias de habla inglesa. La atención pediátrica se hace por la tarde $y$ es de 3 horas (2 a 5 P. M.), siendo este tipo de atención eminentemente preventiva. Las madres, conociendo perfectamente la labor educativa y preventiva de estos Centros, llevan sus hijos enfermos donde su médico particular, - bien, a un determinado servicio hospitalario.

El médico pediatra, además de examinar al niño $y$ controlar su desarrollo y alimentación, es la persona encargada de hacer las inmunizaciones, usando para estos casos la vacuna mixta anti-coqueluche y diftérica, anti-variólica, y en ocasiones, anti-tífica.

En cuanto a la alimentación. la madre recibe por parte del médico las indicaciones dietéticas del caso, teniendo ella que comprar la leche. Estos Centros no proporcionan ninguguna clase de alimentos. En algunas ocasiones puede adquirirse aceite de hígado de bacalao a precios reducidos.

Una vez a la semana funciona en este mismo local una clínica prenatal. Su trabajo es similar al realizado por los consultorios pre-natales que existen en nuestro país. Llama la atención la siguiente nota que el Departamento de Salud envía al médico particular cuando una de sus pacientes ha sido inscrita. En lineas generales dice asi: "Estimado Dr., una de sus pacientes, la Sra. X. X., se ha inscrito en la Clínica Maternal X. X., donde se le controlará su embarazo. Se entiende que cualquiera anormalidad que presente en su desarrollo se la enviaremos para el tratamiento respectivo". Vigilan cuidadosamente el desarrollo del embarazo y una vez producido el parto dan aviso al Centro, acudiendo la enfermera visitadora a imponerse de su estado. Al mismo tiempo, el Director del Centro le envía una carta, recordándole los nuevos deberes que contrae frente a su hijo y felicitándola por la llegada del nuevo ser.

También funciona diariamente un gabinete dental para los niños inscritos en el Centro y los escolares del sector.

En general, todos estos Centros son muy bien conocidos por la población del distrito, la que colabora y coopera en espléndida forma con estos servicios. Lo mismo se puede decir de los médicos, lo que permite, por lo tanto, llevar un control bien detallado del estado sanitario del distrito. Estos Centros y algunas Boticas están autorizadas para otor- 
gar sueto anti-diftérico y antitoxina escarlatinosa gratuitamente, previa receta e indicación médica. También proporcionan vacunas libre de costo para los médicos.

Centro Delorimier: Es un Centro nuevo que aun no ha sido inaugurado. Ocupa un magnífico edificio municipal, donde antes estaba la policía. Está arreglada en la actualidad para acondicionar en sus tres pisos los distintos servicios. Cuenta con una buena sala para biblioteca y otra para conferencias. Su trabajo será similar al de los otros Centros.

Centro Laurier: Funciona en un edificio becho especialmente para Centro de Higiene. La atención pediátrica se realiza en forma parecida a la del Centro Maisonneuve. En el mismo local existe un Centro de Psiquiatría Infantil y de Orientación Profesional, donde acuden los escolares del sector. a quienes se estima conveniente hacerles un estudio mental. Como en los otros grandes Centros funciona un servicio Dental y de Tuberculosis con su equipo correspondiente.

El Departamento de Salud de la ciudad de Montreal ha registrado durante el año 1945 una mortalidad materna de 2.1 por 1,000 nacidos vivos $y$ una mortalidad infantil de 63.1 por 1,000 nacidos vivos. Además de sus funciones en beneficio de la madre y el niño, sus centros sirven de práctica para los alumnos de las cátedras de pediatría y de la salud pública de la ciudad de Montreal, como también para las alumnas de las diferentes escuelas de enfermeras.

Fuera de estas 56 clinicas de higiene infantil dependientes de los servicios municipales de la ciudad, existen 27 clínicas de carácter privado para la atención materno infantil, cuyo trabajo se realiza en íntima coordinación con la División de Higiene Infantil del Departamento de Salud. Tenemos, por ejemplo, la "Federation d'Hygiène Infantil", la que por intermedio de sus Gotas de Leche, posee 19 clínicas infantiles, ubicadas de preferencia en el sector francés de la ciudad y el "Child Welfare Association", institución que atiende de preferencia a la población de habla inglesa. Cuenta con 9 clínicas y está ubicada en la parte oeste de la ciudad.

Child Welfare Association (Asociación de Bienestar Infantil)

Cuenta esta organización con cuatro centros principales, ubicados en diferentes sectores, y cinco centros secundarios. atendiendo un total aproximado de 3 mil lactantes y de 10 mil niños hasta la edad de 6 años. Trabajan en colaboración 
con las cátedras de salud pública y de pediatría de la Universidad de Mc-Gill, estudiando los alumnos en forma práctica todo lo relacionado con la higiene y protección infantil. Las clínicas prenatales coordinan su trabajo con la maternidad Royal Victoria, obteniendo así mejor control sobre la madre y su hijo. En general, el tipo de atención en estos servicios es igual o parecido al que proporcionan los Centros de Higiene Infantil, a los cuales ya nos hemos referido.

Esta Asociación se financia con fondos propios y con una subvención que recibe de parte de la provincia de Quebec y de la Municipalidad de Montreal. Todas las familias inscritas en estos Centros pagan por la atención alrededor de $\mathbf{4}$ a 5 dólares anuales, siendo poquísimas las familias que en determinadas citcunstancias no están en condiciones de hacerlo.

Los médicos pediatras trabajan 2 horas diarias $y$ los Centros funcionan, según el barrio, 3 a 4 veces semanales para la atención de los niños, ya sea en la mañana o en la tarde.

"Child Welfare Center". Richmond Street: Tuve oportunidad de visitar este Centro, cuyo trabajo pediátrico se realiza por la tarde. Funciona en un local anticuado, al que se le han hecho los arreglos necesarios para habitarlo en la mejor forma posible. Cuenta con una amplia y cómoda sala de espera, donde se encuentra el personal auxiliar que controla las citaciones, orden de llegada y el peso de los niños. En otro extremo de la sala puede verse a la enfermera visitadora. atendiendo las diferentes consultas, y la oficina del pediatra. Sus murallas están adornadas con llamativos afiches relacionados con la higiene materno-infantil y con varias vitrinas donde se exhibe ropa para recién nacido y lactantes, con gráficos explicativos para su confección; cunas e incubadoras fáciles de hacer, como también diversos tipos de frascos y chlpetes para mamaderas. Todo esto forma parte del plan de educación sanitaria que el Centro realiza.

En el subterráneo hay una pieza para los pre-escolares y niños pequeños que acompañan a la madre $y$ ésta no tiene dónde dejarlos. El niño encuentra en esa pieza juguetes, mesitas, balancines, etc, $\mathrm{y}$ sus paredes adornadas con diferentes personajes de los cuentos infantiles. Quedan a cargo de una auxiliar, mientras la madre, sola o con su hermanito, visita al médico. En el segundo piso se encuentran las oficinas de la enfermera y una pequeña sala para las charlas y trabajos 
prácticos de las alumnas a enfermeras de la Universidad de Mac-Gill.

Las madres con sus hijos acuden al Centro, previa citación hecha por el médico o la enfermera. Los niños se atienden por orden de llegada, viendo cada médico entre 15 a 20 chicos. A su llegada son atendidos por una auxiliar encargada de buscar la ficha y pesar al niño, pasando después donde la enfermera visitadora, quien interroga a los familiares acerca de Jos diferentes problemas relacionados con el niño, especialmente en los hábitos de higiene. alimentación, etc., pasando finalmente a la oficina del pediatra. Aquí el niño es examinado. se le controla su desarrollo y alimertación. recibe las inmunizaciones correspondientes, previa autorización de la madre, y se investiga la infección tuberculosa.

Como en los otros Centros de Higiene Infantil tampoco recibe leche, solamente proporcionan aceite de hígado de bacalao a bajo precio y, en algunas oportunidades, compuesto a base de fierro.

La enfermera visitadora es la encargada de los controles y visitas domiciliarias, vigilando especialmente la alimentación que el niño recibe, el medio ambiente en que vive, $y$ las condiciones de higiene. Si en sus visitas considera que el niño debe ser visto por el pediatra, le da una citación extraordinaria para que acuda al Centro.

Los enfermos són enviados dénde el médico particular, o bien, a un servicio hospitalario. 